Cahiers $d u$ MONDE RUSSE

\section{Cahiers du monde russe}

Russie - Empire russe - Union soviétique et États indépendants

$46 / 4 \mid 2005$

L'invention d'une politique humanitaire

\title{
Dorena Caroli, L'enfance abandonnée et délinquante dans la Russie soviétique
}

\author{
Gábor T. Rittersporn
}

\section{OpenEdition}

Journals

Édition électronique

URL : https://journals.openedition.org/monderusse/6590

DOI : 10.4000/monderusse. 6590

ISSN : $1777-5388$

Éditeur

Éditions de l'EHESS

Édition imprimée

Date de publication : 1 décembre 2005

Pagination : 897-898

ISBN : 2-7132-2057-2

ISSN : $1252-6576$

Référence électronique

Gábor T. Rittersporn, «Dorena Caroli, L'enfance abandonnée et délinquante dans la Russie soviétique », Cahiers du monde russe [En ligne], 46/4 | 2005, mis en ligne le 29 juin 2009, consulté le 02 septembre 2022. URL : http://journals.openedition.org/monderusse/6590 ; DOI : https://doi.org/ 10.4000/monderusse.6590

Ce document a été généré automatiquement le 2 septembre 2022.

Tous droits réservés 


\title{
Dorena Caroli, L'enfance abandonnée et délinquante dans la Russie soviétique
}

\author{
Gábor T. Rittersporn
}

\section{RÉFÉRENCE}

Dorena CAROLI, L'enfance abandonnée et délinquante dans la Russie soviétique, 1917-1937. Préface de Jutta Scherrer. Paris : L'Harmattan, 2004, 366 p.

1 L'ouvrage de Dorena Caroli convainc le lecteur que le soin apporté aux enfants abandonnés et aux jeunes délinquants est un indicateur caractéristique du fonctionnement de la société soviétique et postsoviétique. Car il n'est sans doute pas exagéré de dire que la besprizornost' est l'une des constantes de celle-ci. L'analyse se limite à l'époque postrévolutionnaire et aux années 1930 ; cependant, il est évident que l'auteur connaît bien ses prolongements dans l'après-guerre ainsi que les questions qui perdurent aujourd'hui et que les enjeux de ses recherches s'inscrivent dans la longue durée.

2 Les ravages de la Première Guerre mondiale, de la révolution et de la guerre civile, et les masses d'enfants qu'elles ont privés de parents et de foyer ne sont sans doute pas imputables uniquement à la politique des bolcheviks. Mais ceux-ci furent incapables de faire face aux problèmes que posait l'enfance abandonnée et d'y apporter des solutions. Ils ont surtout été responsables des difficultés croissantes du pays, qui faisaient de jeunes de plus en plus nombreuxdes réfugiés dans leur propre patrie.

3 La catastrophe de la collectivisation et les centaines de milliers d'enfants qu'elle ajouta à ceux qui avaient été laissés à l'abandon eurent pour cause l'obsession des bolcheviks de réaliser leur projet coûte que coûte. L'exode continu des enfants vers les villes, les jeunes citadins qui erraient dans les rues tout au long des années 1930 furent les conséquences prévisibles de l'appauvrissement dramatique des campagnes, du parti pris d'ignorer les 
laissés-pour-compte de l'industrialisation, et du manque d'empressement du régime à développer une protection sociale.

D. Caroli décrit les efforts postrévolutionnaires pour créer des institutions viables afin de s'occuper des orphelins. L'auteur ne néglige pas les difficultés à mobiliser des ressources, mais elle n'oublie pas que l'État soviétique se chargea de moins en moins du budget des établissements d'accueil. Les autorités locales devaient assumer le gros de la charge, tout en n'en ayant pas les moyens. Le financement alloué par l'État pour protéger les enfants de la rue fut insuffisant tout au long des années 1920 et la situation ne s'améliora guère dans la décennie suivante.

Pourtant, les débuts avaient été plutôt prometteurs. Au cours des premières années du nouveau régime, les institutions chargées des mineurs ne manquèrent pas d'initiatives. Il est intéressant de constater qu'elles reprirent certains éléments du traitement de la délinquance juvénile par l'Ancien Régime. Il s'agissait de mettre sur pied une juridiction spécifique pour les mineurs, mais la législation était tâtonnante et son application laissa à désirer. Il faut dire que les tribunaux n'étaient pas les seuls organes désignés pour prendre en charge le sort de ces jeunes. Des commissions locales devaient examiner les cas d'enfants malfaiteurs et décider s'ils devaient, ou non, être déférés à la justice.

6 Les responsables de ces commissions et des orphelinats ne furent pas insensibles aux théories qu'une multitude d'éducateurs, médecins et psychologues élaboraient sur l'enfance et la délinquance juvénile. Certains travaux reprirent des études médicopédagogiques russes du début du siècle, alors que d'autres s'inspirèrent de l'hypothèse de la déviance morale, dont les origines remontent à la même période. La curiosité à l'égard des études occidentales motiva également les chercheurs soviétiques. L'éventail de ces recherches allait des tentatives pour explorer les causes biologiques de la criminalité de l'enfant et de la prise en charge médicale des mineurs et des orphelins à l'étude des racines sociales des troubles juvéniles. L'État souhaitait cependant que les experts mettent l'accent sur la responsabilité individuelle des jeunes quant à tous leurs actes, y compris ceux commis en situation de détresse.

7 L'éducation par le travail occupa une large place parmi les méthodes que les experts préconisaient, mais il ne fut pas facile de la mettre en œuvre dans des orphelinats mal équipés. Quelques colonies modèles parvinrent à organiser une forme de travail utile pour les jeunes délinquants. Il est d'ailleurs révélateur que les expériences les plus réussies aient été patronnées par la police. Les autres aboutirent pour la plupart à une sorte de formation professionnelle qui ne méritait guère ce nom.

Plus l'enfance abandonnée posa de problèmes, plus le régime fut tenté de renoncer à l'expérimentation - et plus il opta pour des solutions expéditives. Les discussions théoriques cessèrent dans les années 1930 et les commissions chargées des affaires des mineurs finirent par être démantelées. L'État institua la responsabilité criminelle des enfants et se contenta de prendre des demi-mesures, que les autorités locales n'étaient pas à même de financer.

9 Le travail de Dorena Caroli est le seul à établir un bilan des tentatives soviétiques, dans les années 1920 et 1930, pour créer des administrations et des organismes de protection des mineurs en danger. Il s'agit, dans une large mesure, d'une histoire des institutions. Elle restait à écrire et n'était pas facile à élaborer. L'auteur a dû compulser une littérature abondante sur divers aspects de la problématique et surtout retrouver un nombre impressionnant de publications soviétiques qui n'avaient pas été explorées par le passé ; de même il lui a fallu prospecter dans les archives et passer en revue une vaste 
documentation. Espérons que cet ouvrage n'échappera pas à l'attention des chercheurs qui travaillent sur l'enfance en Russie, sur la politique soviétique dans le domaine de la délinquance juvénile et de la justice pénale en général, sur la criminalité des jeunes, sur l'histoire sociale de l'URSS et sur les cataclysmes du xx siècle. 